\title{
EVALUACIÓN DE LA PRUEBA DE INHIBICIÓN DE LA HEMAGLUTINACIÓN vs. ELISA PARA LA DETECCIÓN DE ANTICUERPOS CONTRA Mycoplasma gallisepticum y Mycoplasma synoviae
}

\author{
Beatriz Chirinos Z. ${ }^{1}$, Eliana Icochea . $^{2}$, César Gavidia $\mathrm{Ch}^{3}{ }^{3} \mathrm{y}$ \\ Norma Noé M. $^{3}$
}

\section{Wistriet}

The hemagglutination inhibition test (HI) and an indirect ELISA were used to detect antibodies against Mycoplasma gallisepticum (MG) and M. synoviae (MS) in 102 commercial layer hens from Chincha Province, Ica Department, Peru. The HI test detected MG antibodies in $20 \%$ of the layers tested, whereas ELISA detected its presence in $52 \%$. The frequency of MS reactors detected by HI was $5 \%$ compared to $95 \%$ for ELISA. A polymerase chain reaction (PCR) was set up as a reference test to estimate the sensitivity, specificity, positive and negative prediction values for the HI and ELISA serological tests. The ELISA test was found to be more sensitive for detection of antibodies to MG $(67 \%)$ and MS (97\%) than the HI test which detected low levels of MG (12\%) and MS (5.3\%). The specificity recorded for ELISA was 68\% to MG and 25\% to MS, while the figures for HI were $70.4 \%$ and $100 \%$. The Kappa Index test demonstrates that HI and ELISA produce conflicting results for the diagnosis of MG and MS, and the McNemar test shows that HI can not reliably replace ELISA in this task.

Key words: Mycoplasma gallisepticum, Mycoplasma synoviae, ELISA, HI, PCR, sensibility and specificity.

\section{Teximines}

La prueba serológica de Inhibición de la Hemaglutinación (HI) y una prueba indirecta de Inmunoensayo con Enzimas Asociadas (ELISA) fueron usadas para la detección de anticuerpos contra Mycoplasma gallisepticum (MG) y Mycoplasma synoviae (MS) en 102 gallinas de postura comercial, no vacunadas contra MG y MS, de la provincia de Chincha Departamento de Ica. La prueba de HI detectó anticuerpos contra MG en $20 \%$ de las aves, mientras que la prueba de ELISA detectó un 52\%. Las reactoras a MS fueron de 5 y $95 \%$ para HI y ELISA, respectivamente. La Prueba de la reacción en cadena por la polimerasa (PCR) fue usada como prueba de referencia para la evaluación de sensibilidad, especificidad, valor predictivo positivo, y valor predictivo negativo de $\mathrm{HI}$ y ELISA. La prueba de ELISA fue más sensible para la detección de anticuerpos contra MG $(67 \%)$ y MS $(97 \%)$ que la prueba de HI para MG (12\%) y para MS (5.3\%). La especificidad de la prueba de ELISA para MG y MS fue de $68 \%$ y $25 \%$ y para $\mathrm{HI}$ de $70.4 \%$

1 Práctica privada.

2 Laboratoria de Patología Aviar FMV - UNMSM. E.mail: dI700022@unmsm.edu.pe.

3 Laboratorio de Medicina Veterinaria Preventiva FMV-UNMSM. 
y $100 \%$ respectivamente. Mediante la prueba de Índice de Kappa se determinó que no existe concordancia entre HI y ELISA para el diagnóstico de MG y MS. Asimismo, la prueba de Mc Nemar determinó que HI no puede reemplazar a ELISA.

Palabras clave: Mycoplasma gallisepticum, Mycoplasma synoviae, ELISA, HI, PCR, sensibilidad y especificidad.

\section{Trituduoten}

Una de las enfermedades respiratorias que causa grandes pérdidas es la producida por Mycoplasmas aviares, siendo una constante amenaza en las explotaciones avícolas a nivel mundial. La gravedad de los signos clínicos varía mucho y está condicionada a factores ambientales, virulencia de la cepa de Mycoplasma y factores del ave como edad, propósito de crianza, estrés y manipuleo (Kleven, 1994). Esta enfermedad causa índices de mortalidad del 1 al $10 \%$ y una morbilidad con signos clínicos de 15 a $75 \%$, pudiendo llegar al 100\% (Márquez, 1995). También origina disminución de peso y postura, elevando con ello los costos de producción por tratamiento, además de las pérdidas por decomiso en infecciones crónicas (Ortiz y Kleven, 1992).

En el Perú, la enfermedad se encuentra muy diseminada en las explotaciones avícolas de postura y aves de riña, siendo el Mycoplasma gallisepticum (MG) y el Mycoplasma synoviae (MS), las de mayor importancia clínica y económica (Jordan, 1980; Ortiz y Kleven, 1992). Su transmisión se realiza por contacto directo o por aerosoles, y en forma vertical, siendo esta última la vía más importante de infección de planteles de reproductores. No se conocen los patrones en transmisión por huevo, pero la mayor transmisión de Mycoplasma synoviae se da entre la cuarta y sexta semana después que el ave se infecta (Kleven, 1995; Márquez, 1995). Existe una alta tasa de infección en situaciones en que se mantienen parvadas de edades múltiples, esto sucede principalmente en ponedoras comerciales (Kleven, 1990).

Las técnicas de diagnóstico serológico que se han venido usando en el monitoreo son: aglutinación rápida en placa (SPA) e inhibición de la hemaglutinación (HI), y en la última década se han desarrollado métodos de diagnóstico más sensibles y específicos como ELISA usados para la detección de anticuerpos contra MG y MS, y la Reacción en Cadena por la Polimerasa (PCR) usada para la detección rápida e identificación de Mycoplasmas en muestra de tejido, cultivo y directamente de la tráquea de aves infectadas.

El presente trabajo tuvo por objetivo determinar la sensibilidad, especificidad, valor predictivo positivo y valor predictivo negativo para HI y ELISA y la concordancia entre ambas pruebas serológicas para la detección de anticuerpos contra MG y MS en aves de postura comercial.

\section{Nhronkes y Mams}

Se emplearon 102 muestras de suero de aves de postura comercial entre $25 \mathrm{y}$ 70 semanas de edad y de diferentes líneas genéticas (Harco, Hy line, Isa Brown, Tetra, Shever) no vacunadas contra MG y MS provenientes de granjas ubicadas en la provincia de Chincha, departamento de Ica. La infección por MG y/o MS en las aves fue determinada por la prueba de PCR. 
La detección de anticuerpos contra MG y MS fueron realizadas por la prueba de Inhibición de la Hemaglutinación (HI), usándose cuatro unidades de hemaglutinantes de antígeno SPAFAS para MG y MS y kits comerciales de ELISA (KPL ProFlock) siguiendo las instrucciones del manual del kit comercial.

Para determinar sensibilidad, especificidad, valor predictivo positivo y valor predictivo negativo de HI y ELISA para el diagnóstico de MG y MS se utilizó a la prueba de PCR como referencia basados en el estudio de Gonzales (1999) y para la concordancia entre ambas pruebas se usó la prueba Índice de Kappa (K) y McNemar.

\section{Bosulbutus}

La prueba de ELISA detectó mayor número de reactores a MG y MS que la prueba de HI (Cuadro 1). El análisis de la especificidad de las pruebas de ELISA y HI para MG y MS se observa en los Cuadros 2 y 3 , respectivamente. Asimismo, ELISA demostró tener mayor sensibilidad para la detección de anticuerpos contra MG y MS que la prueba HI (Cuadros 3 y 4 ).

No hubo concordancia entre las pruebas HI y ELISA para el diagnóstico de MG y MS.

\section{Discurion}

Los procedimientos serológicos son utilizados en los programas de monitoreo principalmente en planteles de aves reproductoras para comprobar su condición de libres de Mycoplasma. Esta práctica se da en este tipo de aves para evitar la transmisión del agente a la progenie (Yamamoto, 1990). De las pruebas serológicas usadas, SPA ha sido y sigue siendo la prueba base del monitoreo serológico, mientras que HI y últimamente ELISA son consideradas como pruebas confirmatorias. En el presente estudio se ha comparado la sensibilidad, especificidad y concordancia de las pruebas de HI y ELISA para la detección de anticuerpos contra MG y MS en aves de postura comercial teniendo como prueba de referencia al método de PCR

La prueba de ELISA detectó mayor porcentaje de reactores a MS (95\%) que la prueba $\mathrm{HI}(5 \%)$ y un mayor porcentaje de reactores para MG (52\%) que la prueba HI (20\%) (Cuadro 1). Estos resultados concuerdan con los obtenidos por Ewing et al. (1996a) en muestras positivas a MS por PCR pero difiere con los resultados obtenidos por Ortiz y Kleven (1992) quienes encontraron que ELISA detectó un menor porcentaje de reactores a MS (16\%) que la prueba HI $(21 \%)$. Esta diferencia es probablemente debida al nivel de sensibilidad y especificidad de los kits

Cuadro 1. Detección de anticuerpos contra Mycoplasma gallisepticum (MG) y Mycoplasma synoviae (MS) por las pruebas de Hemaglutinación Indirecta (HI) y ELISA.

\begin{tabular}{lccccc}
\hline Pruebas & $\begin{array}{c}\text { Muestras, } \\
n\end{array}$ & \multicolumn{3}{c}{ MG } & \multicolumn{2}{c}{ MS } \\
\cline { 3 - 6 } & 102 & 20 & 20 & 5 & 5 \\
\hline HI & 102 & 53 & 52 & 97 & 95 \\
ELISA & & & & & \\
\hline
\end{tabular}


de ELISA comerciales usadas en años pasados, actualmente los kits han sido mejorados con la incorporación de un antígeno más purificado y específico otorgándole una mayor sensibilidad y especificidad a la prueba de ELISA. Villegas (1992) menciona que ELISA es una prueba fácil de reproducir con mínima variación de laboratorio a laboratorio, lo que no sucede con la prueba de HI, además de ELISA es muy sensible y puede detectar niveles.muy bajos de anticuerpos.

La prueba de ELISA resultó tener mayor sensibilidad y especificidad frente a HI para detectar anticuerpos contra $\mathrm{MG}$ (Cuadro 2), la baja sensibilidad a MS y MG encontrados en el presente estudio por la prueba de HI comparado con los resultados obtenidos por ELISA (Cuadros $2 \mathrm{y}$ 3 ), puede ser debido al tipo de antígeno usado en la prueba de HI, ya que existe una gran variedad antigénica entre cepas de MG y MS en el campo pudiendo obtenerse reacciones falsas negativas frente al antígeno empleado en la prueba (Kleven et al, 1989; Kleven, 1990; Nepuceno, 1999), además debido a su baja sensibilidad HI no detecta bajos niveles de anticuerpos en infecciones tempranas a diferencia que ELISA y PCR, como lo refieren Edwing et al. (1996b).

En la interpretación de las pruebas serológicas para el diagnóstico de MG y MS no sólo debe importar el número de reactores, sino también la dinámica de los anticuerpos en una parvada entre evaluación y evaluación. Si existe un incremento de aves reactoras el lote esta infectado y son verdaderamente positivos, pero si disminuye lo más probable es que se trate de reacciones falsas positivas (Kleven, 1990; Glisson, 1998).

Cuadro 2. Determinación de la sensibilidad (S), especificidad (E), valor predictivo positivo (VP+) y valor predictivo negativo (VP-) de las pruebas Hemaglutinación Indirecta (HI) y ELISA para la detección de anticuerpos contra Mycoplasma gallisepticum .

\begin{tabular}{lcccc}
\hline Pruebas & $\mathrm{S} \pm \mathrm{I} . \mathrm{C}(\%)$ & $\mathrm{E} \pm \mathrm{I} . \mathrm{C}(\%)$ & $\mathrm{VP}+ \pm \mathrm{I} . \mathrm{C}(\%)$ & $\mathrm{VP}- \pm \mathrm{I} . \mathrm{C}(\%)$ \\
\hline HI & $12.0 \pm 6.3$ & $70.4 \pm 9$ & $35 \pm 9.3$ & $38.0 \pm 9.4$ \\
ELISA & $67.0 \pm 9.1$ & $68.0 \pm 9$ & $74 \pm 8.5$ & $61.0 \pm 9.5$ \\
\hline
\end{tabular}

Cuadro 3. Determinación de la sensibilidad (S), especificidad (E), valor predictivo positivo (VP+) y valor predictivo negativo (VP-) de las pruebas Hemaglutinación Indirecta (HI) y ELISA para la detección de anticuerpos contra Mycoplasma synoviae.

\begin{tabular}{lcccc}
\hline Pruebas & $\mathrm{S} \pm$ I.C $(\%)$ & $\mathrm{E} \pm$ I.C $(\%)$ & VP+ \pm I.C (\%) & VP- \pm I.C (\%) \\
\hline HI & $5.3 \pm 4.3$ & 100 & 100 & $8.2 \pm 5.3$ \\
ELISA & $97.0 \pm 3.3$ & $25.0 \pm 8.4$ & $94 \pm 4.6$ & $40.0 \pm 9.5$ \\
\hline
\end{tabular}


El análisis de Kappa y Mc Nemar demostró la falta de concordancia entre la prueba de HI y ELISA para la detección de anticuerpos contra MG y MS y que la prueba de HI no puede reemplazar a ELISA para el diagnóstico de mycoplasmosis aviar por lo que la prueba de HI no es adecuada como prueba confirmatoria del estado de infección por MS y/o MG del lote y se sugiere que ELISA podría ser considerada como prueba serológica tamiz y PCR como prueba confirmatoria para el diagnóstico de micoplasmosis aviar por MG o MS.

\section{Litrower Chala}

1. Ewing, M.L.; S.H. Kleven y M.B. Brown, 1996a. Comparison of enzimelinked inmunosorbent assay and hamagglutination-inhibition for detection of antibody to Mycoplasmas gallisepticum in commercial broiler, fair and exhibition, and experimentally infute birds. Avian Dis. 41(1): 13-23.

2. Ewing, M.L.; L.H. Lauerman y S.H. Kleven, 1996b. Evaluation of diagnostic procedures to detec Mycoplasmas synoviae in commercial multiplier-breeder farms and commercial hatcheries in Florida. Avian Dis. 40(4): $798-806$.

3. Glisson, J.R. 1998. MG/MS: las vacunas y la bioseguridad. Ind. Avic. Lima 4: $26-27$.

4. Gonzales, V.R. 1999. Detección de Mycoplasmas gallisepticum $y$ Mycoplasmas synoviae mediante el diagnóstico microbiológico PCR en gallinas de postura de la provincia de Chincha. Tesis Licenciatura. Fac. Biol. Univ. Part. Ricardo Palma. Lima, 52p

5. Jordan, F.T. 1980. A survey of Mycoplasmas infections in domestic poultry. Res. Vet. Sci. 28(1): $96-100$.

6. Kleven, S.H.; W. Harry y W. Yoder.
1989. Mycoplasmosis. A laboratory manual for the isolation and identification of avian pathogens. $3^{\text {er }}$ Ed. p57 AAAP. Published by the American Association of Avian Pathologists, p57 - 62.

7. Kleven, S.H. 1995. Current problems with Mycoplasmas synoviae: epidemiology, diagnosis, and control. XIV Congreso Latinoamericano de Avicultura al Sur del Mundo. Chile.,p38 -41 .

8. Kleven, S.H. 1994. Avian Mycoplasmosis In Mycoplasmosis in animals. Laboratory Diagnosis of Whitford $\mathrm{H}$. Edited by Rosenbusch, R. And Lauerman, L. EE.UU., p31 - 38.

9. Kleven, S.H. 1990. Avances en control de micoplasmosis aviar. Avi. Prof. 8(2): $59-63$.

10. Levisohn, S.; D. Menaker y R. Rosengarten. 1995. The effect of surface antigenic variation on diagnosis of Mycoplasmas gallisepticum of poultry. Procedings of the forty-fourth western poultry disease conference. California, p126.

11. Márquez, M.A. 1995. Control y erradicación del Mycoplasmas synoviae en dos integraciones avícolas de progenitoras y reproductoras pesadas. XIV Congreso Latinoamericano de Avicultura al Sur del Mundo. Chile, p18 $-25$.

12. Nepuceno Da Silva, E. 1999. Nuevos conceptos en el control de Micoplasma aviar. IV Seminario Internacional en Ciencias Avícolas. Santa Cruz Bolivia. (del 24 al 27 de Junio de 1999). pp 145 - 148.

13. Ortiz, A. y S.H. Kleven. 1992. Serological detection of Mycoplasmas synoviae infection in turkeys. Avian Dis.36(3): 749-752.

14. Villegas, P. 1992. ¿Sabe lo que significa sus títulos de ELISA?. Ind. Avic. 39(11): 18 . 